\title{
Sobre os casos-limite e os limites das práticas de cuidado em psicanálise
}

\author{
Maria Lívia Tourinho Moretto*1 \\ Daniel Kupermann*2 \\ Christian Hoffmann*3
}

\begin{abstract}
Pretendemos, neste artigo, indicar a relevância da discussão acerca do "limite" na psicanálise. Nos casos-limite é reconhecível o comprometimento na constituição de fronteiras no psiquismo, o que acarreta dificuldades diagnósticas e no manejo transferencial. Propomos que é a indiferença do Outro o que promove a negatividade reativa encontrada nesses casos, fazendo com que, na clínica, a presença sensível do psicanalista seja convocada para a promoção da experiência do cuidado.

Palavras-chave: Estados limítrofes, psicopatologia, transferência, indiferença
\end{abstract}

\footnotetext{
*1 Universidade de São Paulo - USP (São Paulo, SP, Br).

*2 Universidade de São Paulo - USP (São Paulo, SP, Br).

*3 Université Paris Diderot (Paris, França).
} 


\section{Introdução}

Este trabalho se propõe a discutir a noção de caso-limite em uma perspectiva psicanalítica, de maneira a contribuir para a compreensão dos quadros de sofrimento psíquico que se apresentam como verdadeiros desafios aos psicanalistas na contemporaneidade. Referimo-nos a situações clínicas que, do ponto de vista diagnóstico, não se resolvem de acordo com a racionalidade que fundamenta a psicopatologia freudiana, e que fazem os psicanalistas hesitarem entre os diagnósticos estruturais de neurose, psicose e perversão, obrigando-nos, portanto, a rever também os dispositivos que norteiam sua direção do tratamento.

De fato, o modo pelo qual o mal-estar é, nessas situações, apresentado ao psicanalista, não deixa margem à dúvida com relação à sua gravidade, sobretudo naquelas narrativas clínicas que evidenciam a centralidade do corpo como meio privilegiado de expressão do sofrimento, indicando, ao que parece, que as subjetividades em questão não mais encontram meios de representação do excesso pela via da linguagem, restando a alternativa de inscrição no registro corporal.

Nesse sentido, recorremos a um questionamento do conceito de limite e seus estados, não apenas pela sua importância para o campo da psicopatologia psicanalítica, mas, sobretudo, porque esperamos que o aprofundamento dessa problemática auxilie a reflexão que se faz necessária a respeito do método clínico e da direção do tratamento nesses casos. Afinal, os denominados casos-limite nos remetem aos próprios limites da potência transformadora da clínica psicanalítica.

Pretendemos assim, neste artigo, contribuir não apenas para a compreensão metapsicológica dos quadros de sofrimento contemporâneo que indicam os limites do método psicanalítico, mas 


\section{ARTIGOS}

também para fundamentar o aprimoramento e/ou a construção de novos dispositivos clínicos capazes de lhes ofertar atenção e cuidado.

\section{O conceito de limite na clínica psicanalítica}

A ideia de caso-limite na psicanálise tem relação intrínseca, desde sua origem, com noções como borderline, casos fronteiriços, casos difíceis e casos graves. Na verdade, todas essas noções são forjadas a partir de situações clínicas que produzem dificuldades nosográficas relevantes, exigindo dos profissionais o constante questionamento não apenas acerca do diagnóstico, mas também acerca da terapêutica. Esses quadros de sofrimento psíquico se assemelham, em sua estrutura, com aqueles que mereceram o interesse da psiquiatria desde o século XIX (Chagnon, 2009): os estados fronteiriços da loucura, que diziam respeito a casos que não apresentavam sintomas psicóticos manifestos, mas eram considerados formas subclínicas de uma psicose que ainda não havia eclodido.

Figueiredo (2000) ressalta a relação entre os termos borderline preferencialmente utilizado pela tradição inglesa e americana - e casos-limite ou estados limite - empregados pela tradição francesa. Em um primeiro momento, o conceito de limite em psicanálise foi forjado a partir dos esforços de compreensão de casos que não se conformavam à classificação tradicional das estruturas, ou seja, podiam apresentar traços de neurose, psicose e perversão, sendo, ao mesmo tempo, refratários à sua apreensão por qualquer uma dessas categorias. É nesse sentido que Figueiredo (2000) indica a relação entre os termos limite, margem ou borda, presentes na concepção de borderline.

Nessas condições, a noção de limite se relacionaria, em um primeiro momento, com a ideia de instabilidade do quadro psíquico. Por exemplo, estaríamos diante de um caso que, tendo uma estrutura psicótica, apresentava também um funcionamento neurótico temporário ou duradouro - ou vice-versa - mas que indicava, na verdade, uma fragilidade da linha de demarcação entre a neurose e a psicose - sendo que alguns autores concebem essas categorias como estruturas diferentes, enquanto outros consideram-nas relacionadas de um modo contínuo (Chagnon, 2009).

Outra possibilidade de aplicação do conceito de limite, como propôs o pioneiro Kernberg (1984), se faz presente quando nos referimos a uma organização psíquica intermediária entre a neurose e a psicose, que não 


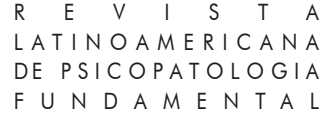

se caracterizaria pela instabilidade, mas pela heterogeneidade, sendo uma estrutura singular e inconfundível.

Entre os clínicos contemporâneos, Hoffmann e Costa (2014) destacam a importância da contribuição do psicanalista francês André Green na pesquisa clínica psicanalítica sobre os "casos graves" com os quais tanto Freud quanto Ferenczi começaram a lidar desde a segunda década do século XX. Green (1988; 2012), ao propor "limite" como conceito psicanalítico, enfatiza a importância da constituição dos limites no aparelho psíquico, indicando que limites internos mal definidos e mal estruturados teriam como consequência as duas formas de angústia características dos casos-limite: angústia de abandono, separação e perda do objeto, e a angústia de invasão ou engolfamento pelo objeto.

Se considerarmos que a história da psicanálise é marcada pela presença constante dos casos difíceis, e que a problematização dos mesmos é o que possibilitou o seu avanço teórico-clínico, são pioneiros no estudo dos casos-limite autores como Freud, Ferenczi, Klein, Winnicott e Lacan, cada um por meio de sua contribuição original.

Em Freud, a noção de limite está presente desde o "Projeto para uma psicologia científica" (Freud, 1895/1974a), uma vez que é a noção de limite que sustenta a proposta de um aparelho psíquico constituído por diferentes instâncias delimitadas por fronteiras, indicando a importância do limite na constituição da subjetividade, e seu caráter determinante na construção da possibilidade de diferenciação não apenas entre as instâncias do aparelho psíquico, mas, como propõe Cardoso (2007), entre o mundo interno e o mundo externo, entre interioridade e exterioridade.

O problema da conceituação de limite e da classificação diagnóstica desses casos vem sendo discutido por vários autores, como ressalta Figueiredo (2003), mas enfatizaremos adiante a contribuição do campo lacaniano, no qual o conceito de limite será, ele próprio, duramente problematizado, em função dos limites desse conceito para a clínica lacaniana em seus diferentes momentos, indicando a insuficiência teórico-clínica tanto do conceito de limite quanto da centralidade do modelo das estruturas clínicas para o diagnóstico dos casos graves, que fogem à condição padrão.

Antes, porém, é preciso indicar que foi o caso do Homem dos Lobos apelido que o paciente Serguéi Pankejeff recebeu de sua segunda analista, Ruth Mack Brunswick - que, segundo Green (2012), inaugurou, na obra de Freud, o estudo dos casos-limite. Green relaciona a aparentemente irredutível "adesividade da libido" do Homem dos Lobos, cuja maior expressão foi a 


\section{ARTIGOS}

transferência interminável a Freud, à angústia de separação característica dos casos-limite e às manifestações transferenciais dela decorrentes.

Pode-se, de fato, considerar que este caso chamou a atenção do campo psicanalítico pelo fato de Brunswick (1928/1981) ter diagnosticado uma paranoia hipocondríaca onde Freud (1918/1974c) reconheceu uma neurose obsessiva grave. Ou seja, se evitarmos a solução fácil de que um dos dois analistas cometera erro diagnóstico, pode-se efetivamente considerar que o analisando se apresentou neurótico para o primeiro analista e psicótico para o segundo, transformando-se, assim, no primeiro borderline da história da psicanálise (Kupermann, 2014).

\section{Os limites da clínica psicanalítica}

Na clínica contemporânea, é da experiência com adolescentes "graves" que Hoffmann (2013) indica a irrupção de uma cólera que se transforma em atos de violência contra o próprio corpo e em comportamentos autodestrutivos. A dor corporal que esses adolescentes se proporcionam - por meios vários que vão desde os cortes, as escarificações, até as tentativas de suicídio - funcionaria como uma tentativa de aliviar a dor do ser, ou seja, a dor de existir.

Uma hipótese de trabalho pode ser considerada nessa situação: os atos de autodestruição podem indicar uma mudança de rota pulsional, um deslocamento para si do desejo de destruição do outro. E o que torna isso possível? Não há, nesses quadros de sofrimento, diferença entre se destruir e destruir o outro? Não há limite no aparelho psíquico que faça barreira aos atos autodestrutivos?

Ainda para Hoffmann (2013), a clínica com adolescentes em risco nos faz redescobrir a relação entre agressividade e erotismo, nos remetendo imediatamente a dois textos de Freud: "Mal-estar na civilização" (Freud, 1930/1974f), para a compreensão da relação entre o furor destrutivo sem intenção sexual e o gozo narcísico do $\mathrm{Eu}$, satisfazendo desejos arcaicos de onipotência; e o "O ego e o id" (Freud, 1923/1974d), no qual Freud propõe a segunda tópica do aparelho psíquico, de onde extrai-se a hipótese de que nesse modelo de funcionamento psíquico o Eu não tem verdadeira fronteira com o Isso, mas sua relação com o mundo exterior é marcada por um limite. De onde vem esse limite (do Eu com o mundo externo)? O que, na constituição do psiquismo, limita (ou limitaria) o gozo narcísico e a onipotência? Não se 


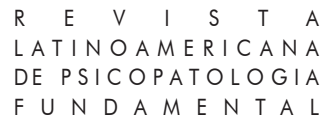

constata, efetivamente, nesses casos, uma diferenciação clara entre o $\mathrm{Eu}$ - ou o que é meu - e o outro - ou o que é do outro.

O mais provável é que essa não diferenciação que caracteriza os casos-limite se deva, ao menos em parte, ao não estabelecimento ou a problemas no estabelecimento de limites na constituição do psiquismo.

A consideração dessa hipótese — de que há problemas no estabelecimento de limites na constituição do psiquismo - nos parece ser importante para a discussão a respeito das dificuldades que o analista encontra no manejo clínico com casos-limite, pela via da transferência. Algumas dessas dificuldades são decorrentes do contato com a intensidade e com o primitivismo dos mecanismos presentes nesses atendimentos (Coelho Júnior \& Getlinger, 2006), exigindo do analista, no mínimo, certa elasticidade psíquica que lhe permita ter clareza não apenas da complexidade da situação como também, e em especial, de sua relação com os seus próprios limites (Savietto \& Figueiredo, 2012).

Que tipo de relação transferencial se estabelece nessas condições? De que maneira a não diferenciação ou a falta de limites se apresenta na relação com o analista? Partimos da hipótese de que a falta de limites na constituição

102 do psiquismo possibilitaria a constituição de subjetividades aqui denominadas de casos-limite que, por sua vez, evidenciam os limites do dispositivo clínico psicanalítico na condução desses casos. Cabe-nos, neste momento, explorar o tema das origens do limite na constituição do psiquismo, e da importância da alteridade (tanto interna quanto externa) para a compreensão e o tratamento dessas modalidades de sofrimento.

\section{Metapsicologia do limite}

Hoffmann (2013) evoca a hipótese freudiana de que esse limite na constituição subjetiva vem da experiência da perda de um objeto e de seu gozo. É a perda de um objeto anteriormente reconhecido como parte do corpo que permite o estabelecimento do limite entre o $\mathrm{Eu}$ e o mundo exterior. Seria, portanto, a experiência de perda do objeto de gozo - que doravante, na qualidade de objeto perdido, aparece para o Eu como um "de fora" que possibilitaria a constituição do limite psíquico entre o que é interno e o que é externo, entre prazer e desprazer e, finalmente, entre Eu e outro. A importância da falta na relação com o Outro deixa claro o privilégio dado à alteridade no estabelecimento dos limites do/no aparelho psíquico e a 


\section{ARTIGOS}

condição (não a garantia) de diferenciação tanto entre as instâncias psíquicas quanto entre o Eu e o mundo externo.

E é justamente a condição psíquica de reconhecimento das diferenças e de estabelecimento de limites entre Eu e outro que permite a ação civilizatória e de integração com a cultura, funcionando como barreira à hetero e à autodestruição.

Dessa maneira, se o estabelecimento do limite no aparelho psíquico faz barreira à tendência mortífera, então a falta de limite levaria à autodestruição (como notamos na clínica dos adolescentes à qual nos referimos acima), e isso nos exige uma compreensão mais clara a respeito da origem da agressividade e da natureza metapsicológica dessas tendências mortíferas em sua relação com a constituição do Eu. Segundo Freud (1895/1974a; 1911/1974b), decorre também da experiência de perda de objeto de gozo, para além do estabelecimento do limite, a aquisição de duas competências cruciais para o funcionamento psíquico: as faculdades de pensar e de julgar (juízo de atribuição e juízo de existência). O "Eu prazer", afirma ainda Hoffmann (2013), totalmente ocupado com o gozo íntimo dele mesmo, não é suficiente para transformar a percepção em representação refletida e apreendida pela experiência.

Nesse sentido, como devedoras da experiência de perda de gozo/ experiência de negatividade (Freud, 1925/1974e), a partir de então, as faculdades de pensar e de julgar se impõem ao circuito pulsional como experiência de desejo que permanece como falta, sendo ambos - pensamento e julgamento - decisivos tanto para a realização quanto para a postergação das ações.

Dessa maneira, propomos, em primeiro lugar, que o entendimento de certas manifestações — como, por exemplo, a angústia de separação borderline e as manifestações transferenciais dela decorrentes — se faça a partir da escuta clínica da presença ou não da experiência da falta na constituição subjetiva, o que, por sua vez, nos indicaria o tipo de relação que um sujeito estabelece com os limites e com a instauração do princípio de realidade, uma vez que o "Eu realidade" barra o gozo narcísico e onipotente do "Eu prazer" pelo reconhecimento do mundo exterior e da cultura.

Porém, se reconhecemos a importância da experiência de perda de gozo e da experiência da falta para a constituição das faculdades de julgar e de pensar, e dos limites entre Eu e outro, prazer e realidade, interno e externo, o que, por sua vez, favorece a constituição dessa experiência? De que modo se dá a experiência de perda para o sujeito? 


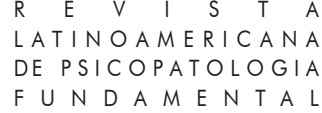

A clínica nos ensina que há diferentes formas de negatividade ou de transmissão da falta, tal como teoriza Lacan (1956-1957/1995) em seu seminário sobre as relações de objeto, ao se referir às diferenças entre castração, privação e frustração. Essas diferentes formas de negatividade indicam, consequentemente, diferenças na constituição das subjetividades em questão. Qual a natureza da falta que possibilita o estabelecimento dos limites (dentro/fora; Eu/outro; prazer/desprazer) fazendo barreira ao gozo narcísico? Nos casos-limite, a perda/falta pode ser entendida como a mesma falta que possibilitaria a constituição de um sujeito regido pela lógica do desejo, representante desta mesma falta? Ou seja, é possível relacionarmos a experiência da falta nos casos-limite com a noção de castração simbólica/ recalque? Ou deveríamos pensar, nos casos-limite, a experiência de perda/ falta não com a noção de castração simbólica, mas com as noções de privação e de frustração?

Ainda que a experiência da falta proporcionada na relação com Outro produza desprazer, entendemos que sem essa experiência de perda, o que temos é a experiência da falta da falta. Nesse caso, quando falta a falta, poderíamos considerar inicialmente duas consequências: a constituição de subjetividades

104 psicóticas ou os casos-limite. Que operação psíquica os diferencia?

Ou não se constitui, no aparelho psíquico, a condição de diferenciação entre Eu e outro, ou essa condição de diferenciação ficaria manca, falha, na medida em que o limite, não estando consolidado, dificultaria o delineamento suficientemente claro das fronteiras e das instâncias psíquicas, bem como entre o Eu e o outro (interno-externo). Estaríamos, na primeira hipótese, diante de casos de psicose, enquanto a segunda estaria referida, propriamente, ao que deveríamos chamar de "casos-limite"?

\section{Sobre a angústia de separação e o vazio da existência nos casos-limite}

A clínica com os casos-limite nos permite escutar com frequência o sofrimento dos pacientes relativo à angústia de separação e ao vazio da existência. Há casos em que a perda do objeto de gozo é uma experiência da ordem do intolerável, de tal modo que, não podendo perder o objeto - não suportando a separação do objeto - não há o estabelecimento de fronteiras que delimitam diferenças entre Eu e outro. Desse modo, o que ocorre é a fusão do sujeito com o objeto, talvez em busca de alguma garantia de amparo frente a experiência do vazio da existência. 


\section{ARTIGOS}

Os relatos clínicos indicam, no entanto, que esse vazio da existência é diferente do sofrimento apresentado pelo sujeito neurótico a partir da experiência da castração, no sentido de que este último experimenta o vazio a partir de suas bordas, enquanto o sujeito borderline, por sua vez, estaria verdadeiramente à beira do precipício, sem qualquer borda para se agarrar.

Isso é tão significativo na narrativa de sofrimento que o que escutamos, com frequência, são relatos que nos indicam a inexistência de experiências de satisfação (Macedo, 1999) e a imensa dificuldade de transformar sonhos e fantasias em humor e brincadeira (Figueiredo, 2000). Green (2012) ressalta que os casos-limite nos obrigam a pensar em modalidades defensivas diferentes do recalque. Não é gratuito que alguns autores (Kupermann, 2014), seguindo uma filiação que começa com Ferenczi e ganha corpo com Winnicott, indicam que os casos-limite apresentam um comprometimento em sua constituição narcísica grave o suficiente para, em vez de experimentarem o que conhecemos como angústia de castração, encontram-se submetidos às "ansiedades impensáveis" diante de qualquer situação de ameaça de separação dos objetos que lhes oferecem a oportunidade de alguma estabilidade, ainda que fragilíssima.

Um outro olhar sobre os casos-limite:

a indiferença como forma de negatividade

Pelo argumento desenvolvido até o momento, percebe-se a relação estreita entre o conceito de limite e o estabelecimento do princípio de realidade em Freud, que possibilita, inclusive, a origem das faculdades de pensar e de julgar, uma vez que elas seriam de responsabilidade do Eu-Realidade, e orientariam a tomada de decisão das ações do sujeito. O juízo, por seu turno - seja ele juízo de atribuição de valor (dentro/fora), seja ele juízo de existência (está ou não está na realidade) —, resulta do estabelecimento de um limite que possibilita e favorece a diferenciação entre $\mathrm{Eu}$ e outro. Mas a clínica nos indica que, mesmo entre aqueles que consideramos razoavelmente ajuizados, a condição metapsicológica de diferenciação entre $\mathrm{Eu}$ e outro não equivale, necessariamente, ao reconhecimento dessa diferenciação nas relações intersubjetivas.

Referimo-nos a casos onde a problemática central do sofrimento parece ter fonte na dificuldade considerável do sujeito no que tange ao reconhecimento dessas diferenças, de tal modo que muitas vezes ele se mostra 
indiferente aos limites, ou, dito de outro modo, indiferente às diferenças, tomando o outro como parte de si, como se a função do outro fosse, ainda, a satisfação do gozo narcísico.

Note-se que, nesse ponto, é preciso enfatizar que o problema do sofrimento relatado pelo sujeito não se relaciona, do ponto de vista dele próprio, nem com o conhecimento nem com o desconhecimento das diferenças, mas sua dificuldade reside no reconhecimento das mesmas, de tal modo que o efeito do não reconhecimento dos limites indica, para além do vazio de existência ao qual já nos referimos, uma dificuldade real de reconhecimento do Outro. Isto porque o reconhecimento legítimo não é aquele que toma por conteúdo os atributos imaginários de um sujeito, mas o que lhe permite se dirigir a um Outro sustentando sua demanda, fazendo valer o desejo que resulta do estabelecimento das diferenças.

É por essa razão que, muitas vezes, na tentativa de ampliarmos o escopo teórico que fundamenta nossa clínica, temos pensado que o tipo de sofrimento que encontramos no que se tem denominado de "casos-limite" possa não estar apenas ligado à falta da experiência da falta/perda de objeto de gozo. Talvez a consideração de um outro tipo de negatividade seja para nós decisiva na compreensão metapsicológica da constituição da subjetividade dos casos-limite: a indiferença do Outro, que tem consequências nefastas para a constituição subjetiva do infans.

De fato, para Freud (1911/1974b) o que faz oposição real ao amor não é o ódio nem o apelo ao ser amado; para ele o que faz oposição real ao amor é a indiferença. Se no amor e no ódio não restam dúvidas a respeito da existência do Outro na constituição das subjetividades, na indiferença essa existência fica questionada, o que dificulta, se é que não impossibilita, a condição psíquica de reconhecimento mútuo.

A clínica psicanalítica sugere que todo sofrimento traz consigo uma demanda de reconhecimento, de tal modo que se pode dizer que o não reconhecimento do seu sofrimento é proporcional à dificuldade que um sujeito encontra para nomear o seu mal-estar (Dunker, 2015). Por outro lado, notamos que a narrativa de sofrimento se transforma quando, em um dispositivo clínico, para além de escutar o sujeito, o Outro o reconhece em sofrimento, desde a sua radical singularidade.

É nessa direção que consideramos que a indiferença como forma de negatividade articulada ao sofrimento nos "casos-limite" pode nos fazer lançar um outro olhar sobre o entendimento dos mesmos, o que nos exigiria, certamente, estender esse outro olhar para a discussão a respeito do manejo clínico da transferência nesses casos. 


\section{ARTIGOS}

Parece-nos bastante razoável a hipótese de que no campo da alteridade, a indiferença do Outro é um elemento que não favorece o estabelecimento de limites no aparelho psíquico em constituição, nem tampouco a emergência de modos de subjetivação afinados com a criatividade e com a singularidade.

\section{Considerações finais}

O que nos chama atenção na clínica dos casos-limite é o modo pelo qual nos são apresentadas as narrativas de sofrimento nesses casos: é uma narrativa sem implicação, sem questionamento, sem historicidade, sem autoria. Estamos diante de pessoas que se apresentam em sofrimento e/ou apresentam seus corpos em sofrimento, por meio de uma narrativa focada na informação (diferente da queixa), que afirma a presença de sentimentos de inutilidade, a sensação frequente de que a vida é a expressão do vazio de sentido, a convicção de que lhes falta originalidade, criatividade; a vida dessas pessoas é, segundo elas, uma mesmice.

Então, ali onde Freud encontrou um sujeito da queixa, com frequência o que encontramos em nossa frente é um informante. O curioso é que o nosso informante, a despeito de sua relação de exterioridade com o sofrimento que experimenta, apresenta-se, ele próprio, disposto a oferecer-se ou a oferecer seu corpo não tanto para uma escuta que fundamentaria a clínica psicanalítica, mas para investigação científica, como se o corpo não fosse seu, numa relação onde também pouco importa para ele a identidade desse Outro que, ele supõe, o tomará como objeto de sua investigação. É como se pudéssemos inferir da posição subjetiva de nosso informante a frase seguinte: "O Outro me é indiferente".

Oferecendo-se ao Outro indiferente como objeto, tem-se que a demanda de nosso informante não passa pelo pedido de tratamento da dor da perda, o que é compreensível se levarmos em conta a metapsicologia dos limites que tomamos como referência para a compreensão dos casos. Nesse cenário, ele não se refere a um objeto perdido orientando sua narrativa de sofrimento. E se não há perda, pergunta-se: como é possível proceder ao trabalho de elaboração de lutos nesses casos? Como a clínica psicanalítica possibilita o tratamento desse sofrimento?

Pensamos que é porque a constituição da subjetividade se dá no campo da alteridade que podemos dizer que a possibilidade de mudanças das posições subjetivas de um sujeito se dão, também, no campo da alteridade 


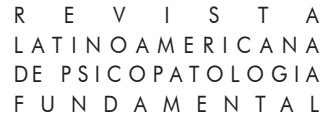

— portanto, no laço social —, como se pode constatar por meio do dispositivo clínico psicanalítico, sob transferência.

É nesse sentido que se faz urgente a revisão dos dispositivos clínicos psicanalíticos no acolhimento desses casos, em que é razoável pensar que a retificação subjetiva exigiria do analista, antes, intervenções que possibilitassem a retificação do Outro por meio da transferência.

$\mathrm{O}$ analista é este que está atento ao fato de que todo sofrimento traz em si a demanda de reconhecimento e está advertido do impossível de gozo na alteridade.

A clínica dos casos-limite o convoca, a partir disso, a buscar as coordenadas éticas para a discussão a respeito de sua posição no dispositivo da transferência, uma vez que o mais provável nesses casos é que o manejo da transferência implique acolher analisandos que tendem a identificar-se com seus analistas em busca da alienação que os acalma, tornando a análise um empreendimento interminável.

Então, diante de um cenário em que a presença do sujeito parece improvável, eis a aposta do analista: há de haver um sujeito aí. Esta aposta é sustentada pelo que Lacan (1958-1959/inédito) chamou de desejo do analista que é, por sua vez, desejo de pura diferença. O desejo do analista é o desejo de que o sujeito produza sua mais absoluta diferença. É preciso, portanto, que não fiquemos indiferentes a ele.

É nesse ponto final que outros desafios retornam à cena e nos convocam à continuidade: nesses casos, especialmente, a clássica noção de neutralidade/ abstinência do analista, se tomada ao pé da letra, pode se confundir com uma posição de indiferença por parte do analista.

Para que a análise possa produzir qualquer efeito sobre o sujeito que sofre, é preciso que consideremos que, como consequência do potencial traumático da posição de indiferença por parte do analista no tratamento dos casos-limite, encontraríamos o risco maior: a produção dos efeitos iatrogênicos da psicanálise e a cronificação do sofrimento.

Certamente, não é isso o que de melhor a psicanálise tem a oferecer às demandas a ela dirigidas. Convém reafirmar que o estilo clínico aqui proposto exige trabalho e presença sensível do analista na oferta de cuidado ao sofrimento das pessoas envolvidas e na atenção à singularidade de cada caso. 


\section{ARTIGOS}

\section{Referências}

Brunswick, R. M. (1981). Supplément à l'“Extrait de l'histoire d'une névrose infantile" de Freud. In M. Gardiner (Org.), L'Homme aux Loups par ses psychanalystes et par lui-même (M. Bonaparte, trad., pp. 268-316). Paris: Gallimard. (Trabalho original publicado em 1928).

Cardoso, M. R. (2007). A impossível "perda" do outro nos estados-limites: explorando as noções de limite e alteridade. Psicol. rev., 13(2), 325-338.

Chagnon, J-Y. (2009). Os estados-limite nos trabalhos psicanalíticos franceses. Psicol. USP, 20(2), 173-192.

Coelho Júnior, N. E., \& Getlinger, P. V. (2006). Fronteiras no trabalho clínico com casos-limites. J. Psicanal., 39(71), 151-169.

Dunker, C. I. L. (2015). Mal-estar, sintoma e sofrimento. São Paulo, SP: Boitempo.

Figueiredo, L. C. (2000). Os casos-limite e as sabotagens do prazer. Revista Latinoamericana de Psicopatologia Fundamental, 3(2), 61-87.

Figueiredo, L. C. (2003). Psicanálise: elementos para a clínica contemporânea. São Paulo, SP: Escuta.

Freud, S. (1974a). Projeto para uma psicologia científica. In Edição Standard Brasileira das Obras Psicológicas Completas de Sigmund Freud (Vol. I). Rio de Janeiro, RJ: 1mago. (Trabalho original publicado em 1895).

Freud, S. (1974b). Formulações sobre os dois princípios do funcionamento mental. In Edição Standard Brasileira das Obras Psicológicas Completas de Sigmund Freud (Vol. XII). Rio de Janeiro, RJ: lmago. (Trabalho original publicado em 1911).

Freud, S. (1974c). História de uma neurose infantil ("O homem dos lobos"). In Edição Standard Brasileira das Obras Psicológicas Completas de Sigmund Freud (Vol. XIV). Rio de Janeiro, RJ: lmago. (Trabalho original publicado em 1918).

Freud, S. (1974d). O ego e o id. In Edição Standard Brasileira das Obras Psicológicas Completas de Sigmund Freud (Vol. XIX). Rio de Janeiro, RJ: Imago. (Trabalho original publicado em 1923).

Freud, S. (1974e). A negativa. In Edição Standard Brasileira das Obras Psicológicas Completas de Sigmund Freud (Vol. XIX). Rio de Janeiro, RJ: Imago. (Trabalho original publicado em 1925).

Freud, S. (1974f). Mal-estar na civilização. In Edição Standard Brasileira das Obras Psicológicas Completas de Sigmund Freud (Vol. XXI). Rio de Janeiro, RJ: Imago. (Trabalho original publicado em 1930).

Green, A. (1988). A loucura pessoal do analista. Rio de Janeiro, RJ: Imago.

Green, A. (2012). La clinique psychanalytique contemporaine. Paris: Ithaque. 


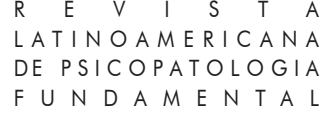

Hoffmann, C. (2013) Le concept de limite dans l'inconscient et ses états. In Hoffmann, C. e Lauru, D. (Orgs.) Figures de la psychanalyse, n.25, Paris: Erès.

Hoffmann, C. \& Costa, R. A. (2014). Alguns casos, nem neuróticos, nem abertamente psicóticos. Ágora, 17(2), 247-253.

Kernberg, O. (1984). Les troubles graves de la personnalité: stratégies psychothérapiques. Paris: PUF.

Kupermann, D. (2008). Presença sensível: cuidado e criação na clínica psicanalítica. Rio de Janeiro, RJ: Civilização Brasileira.

Kupermann, D. (2014). A maldição egípcia e as modalidades de intervenção em Freud, Ferenczi e Winnicott. Revista Brasileira de Psicanálise, 48(2), 47-58.

Lacan, J. (1995). O seminário. Livro 4. A relação de objeto. Rio de Janeiro, RJ: Jorge Zahar. (Trabalho original publicado em 1956-1957).

Lacan, J. (inédito). O seminário. Livro 6. O desejo e sua interpretação. Edição Eletrônica em CD-ROM dos Seminários e Escritos de Jacques Lacan [CD-ROM]. Buenos Aires: Escola Freudiana de Buenos Aires. (Trabalho original publicado em 1958-1959).

Macedo, H. O. (1999). Do amor ao pensamento. São Paulo: Via Lettera.

Savietto, B. B. \& Figueiredo, L. C. (2012). Elasticidade e limite na clínica da drogadicção: por um pensamento clínico complexo. Cad. psicanal., 34(27), 119140 .

\section{Resumos}

(On borderline cases and the boundaries of care within psychoanalysis)

In this paper, we point out the relevance of discussing "boundaries" within psychoanalysis. In borderline cases, it is possible to identify the lack of boundaries established within the psyche, resulting in problems concerning diagnosis and the management of transference. We suggest that it is the indifference of the Other that encourages the reactive negativity that we find in these cases; in clinical practices, the sensitive presence of the psychoanalyst is called upon to promote the experience of care.

Keywords: Borderline states, psychopathology, transference, indifference

(Des cas limites et les limites des pratiques de soins en psychanalyse)

Cet article vise à élucider la pertinence de la discussion sur la "limite" en psychanalyse. Dans les cas limites, nous remarquons l'engagement d'établir des limites au psychisme, ce qui crée des difficultés en ce qui concerne le diagnostique et la gestion du transfert. Nous proposons que c'est l'indifférence de l'Autre qui 


\section{ARTIGOS}

encourage la négativité réactive que l'on retrouve dans ces cas, ce qui exige, en clinique, la convocation de la présence sensible du psychanalyste pour promouvoir l'expérience du soin.

Mots clés: États limitrophes, psychopathologie, transfert, indifférence

(Sobre los casos límite y los límites de las prácticas de cuidado en psicoanálisis)

Pretendemos, en este artículo, indicar la relevancia de la discusión sobre los "límites" en el psicoanálisis. En los casos límite, se reconoce el compromiso en la formación de fronteras en el psiquismo, lo que resulta en dificultades diagnósticas $y$ en el manejo transferencial. Proponemos que es la indiferencia del Otro la que fomenta la negatividad reactiva encontrada en estos casos, haciendo que, en la práctica clínica, la presencia sensible del psicoanalista sea convocada para fomentar la experiencia del cuidado.

Palabras clave: Estados limítrofes, psicopatología, transferencia, indiferencia

(Grenzfälle und die Grenzen der Behandlung in der Psychoanalyse)

In diesem Artikel beabsichtigen wir, die Relevanz der Diskussion der ",Grenze“ in der Psychoanalyse darzustellen. Grenzfälle offenbaren die Unzulänglichkeit, psychische Grenzen zu setzen, was die Diagnose und die Handhabung der Übertragung erschwert. Wir vertreten die Ansicht, das die Gleichgültigkeit des Anderen in diesen Fällen eine reaktive Negativität verursacht, was dazu führt, dass in der Klinik die persönliche Anwesenheit des Psychoanalytikers unabdingbar ist, um die Erfahrung der Behandlung anzuregen.

Schlüsselwörter: Grenzzustände, Psychopathologie, Übertragung, Gleichgültigkeit

\section{（关于临床案例的边界线和护理在精神分析中的界限）}

在这篇文章, 我们希望探讨精神分析中的有关 “界限” 的相关问题。在 临床案例中, 病人的行为和心理状态经常是模糊的, 从而增加专业人员的诊断 难度和心理疏导的困难。我们认为病人对 “他者”的冷漠引发了临床案例中的 消极反应, 需要专业人员的干预性护理。

关键词: 临界面, 精神病理学, 移情, 冷漠。

Citação/Citation: Moretto, M. L. T., Kupermann, D., \& Hoffmann, C. (2017, março). Sobre os casos-limite e os limites das práticas de cuidado em psicanálise. Revista Latinoamericana de Psicopatologia Fundamental, 20(1), 97-112. 


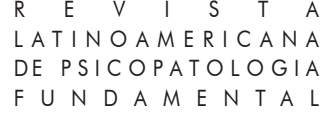

Editores do artigo/Editors: Profa. Dra. Ana Maria Rudge e Profa. Dra. Sonia Leite

Recebido/Received: 9.10.2016/ 10.9.2016 Aceito/Accepted: 19.12.2016/12.19.2016

Copyright: (C) 2009 Associação Universitária de Pesquisa em Psicopatologia Fundamental/ University Association for Research in Fundamental Psychopathology. Este é um artigo de livre acesso, que permite uso irrestrito, distribuição e reprodução em qualquer meio, desde que o autor e a fonte sejam citados / This is an open-access article, which permits unrestricted use, distribution, and reproduction in any medium, provided the original authors and sources are credited.

Financiamento/Funding: Os autores declaram não terem sido financiados ou apoiados / The authors have no support or funding to report.

Conflito de interesses/Conflict of interest: Os autores declaram que não há conflito de interesses / The authors have no conflict of interest to declare.

\section{Maria Lívia Tourinho Moretto}

Psicanalista; Professora Doutora do Departamento de Psicologia Clínica do Instituto de Psicologia da Universidade de São Paulo - USP (São Paulo, SP, Br); Membro da Associação Universitária de Pesquisa em Psicopatologia Fundamental (São Paulo, SP, Br). Av. Professor Mello Moraes, 1721, bloco F, sala 24 - Cidade Universitária 05508-030 São Paulo, SP, Br.

liviamoretto@usp.br

\section{Daniel Kupermann}

Psicanalista; Professor Doutor do Departamento de Psicologia Clínica do Instituto de Psicologia da Universidade de São Paulo - USP (São Paulo, SP, Br): Bolsista do CNPq (Brasília, DF, Br).

Av. Professor Mello Moraes, 1721, bloco F, sala 28 - Cidade Universitária 05508-030 São Paulo, SP, Br.

danielkupermann@gmail.com

\section{Christian Hoffmann}

Psicanalista; Diretor da École Doctorale Recherches en psychanalyse et en psychopathologie - Université Paris Diderot - PRES Sorbonne Paris Cité

26 rue de Paradis

75010 Paris, França

hoffmann.ch@wanadoo.fr

This is an open-access article, which permits unrestricted use, distribution,
and reproduction in any medium for non-commercial purposes provided
the original authors and sources are credited.

Rev. Latinoam. Psicopat. Fund., São Paulo, 20 (1), 97-112, mar. 2017 